\title{
Meduloepitelioma teratóide maligno do globo ocular: relato de caso e revisão da literatura
}

\section{Intraocular malignant teratoid medulloepithelioma: case report and review of the literature}

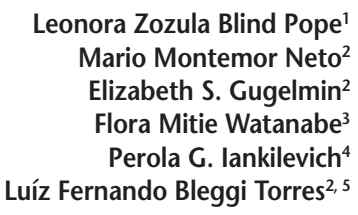

\section{unitermos resumo}

Diktioma

Os autores relatam um caso de meduloepitelioma teratóide maligno intra-ocular acometendo

Meduloepitelioma

uma menina de 7 anos com história de glaucoma congênito. O padrão histológico demons-

Neoplasia do corpo ciliar

trou ilhas de epitélio primitivo, com freqüentes estruturas tubulares e focos de cartilagem.

Após procedimento cirúrgico, a paciente encontra-se bem, sem evidência de recorrência

tumoral.

\section{abstract}

The authors report a case of intraocular malignant teratoid medulloepithelioma affecting a seven years old girl with congenital glaucoma. The histological sections showed areas of primitive and undifferentiated cells, with frequent tubular formations and foci of mature hyaline cartilage. After surgical treatment the patient is well and free of recurrence.

key words

Diktyoma

Medulloepitheliome

Neoplasm of the ciliary body

\section{Introdução}

Meduloepitelioma intra-ocular é uma rara neoplasia embrionária, originada do epitélio ciliar nãopigmentado indiferenciado. Apresenta crescimento lento, sendo localmente agressivo e com metástases à distância infreqüentes. Acomete crianças e, preferencialmente, o corpo ciliar (1). Foi reconhecido e designado como carcinoma primitivo por Badel e Lagrange em 1892 (2). Verhoeff descreveu outro caso em 1904 (3), o qual denominou "teratoneuroma", apesar de este não conter elementos teratóides. Fuchs relatou caso similar em 1908 (4), com presença de células pouco diferenciadas arranjadas em cordões, o qual denominou "diktioma", derivado do radical grego que significa rede. Esta designação não inclui as características citológicas e embrionárias da lesão, mas continua o termo mais popular para esta lesão. A designação "meduloepitelioma" foi utilizada pela primeira vez em 1931, por Grinker (5).

O presente relato descreve o caso de uma criança de 7 anos, do sexo feminino, com história de glaucoma há um ano, sendo posteriormente diagnosticada, após enucleação, como portadora de meduloepitelioma teratóide maligno intra-ocular.

\section{Relato do caso}

Paciente do sexo feminino, 7 anos, com exoftalmia e diminuição da visão há dois anos, em olho direito, por glaucoma congênito. Há um ano foi submetida a cirurgia para glaucoma fistulizante, permanecendo com dreno intra-ocular pós-operatório. Tomografia pós-operatória mostrou massa intra e extra-ocular resi-
1. Residente em patologia, Departamento de Patologia Médica, Universidade Federal do Paraná (UFPR).

2. Médico patologista do Hospita Infantil Pequeno Príncipe.

3. Médica oncologista pediátrica do Hospital Infantil Pequeno

Príncipe.

4. Médica oftalmologista pediátrica do Hospital Infantil Pequeno Príncipe. 5. Professor titular de patologia médica, Departamento de Patologia Médica (UFPR). 
dual com necrose conjuntival, sendo realizada subseqüente enucleação, com saída de múltiplos fragmentos irregulares, medindo, no conjunto, $2,5 \mathrm{~cm} \times 2,5 \mathrm{~cm} \times 1,5 \mathrm{~cm}$, de coloração cinza esbranquiçada, foscos e macios.

Cortes histológicos corados por hematoxilina e eosina demonstraram uma neoplasia composta por cordões anastomosantes (Figura 1) infiltrando a esclera e o corpo ciliar (Figura 2). Os cordões eram formados por células cúbicas e poliédricas, com citoplasma eosinofílico, núcleos centrais, nucléolos inconspícuos e figuras de mitose ausentes (Figura 3). Observou-se presença de ilhas formadas por células pequenas, arredondadas, com citoplasma escasso e núcleos hipercromáticos em meio a uma matriz eosinofílica e fibrilar, PAS positiva, formando lençóis. Tam-

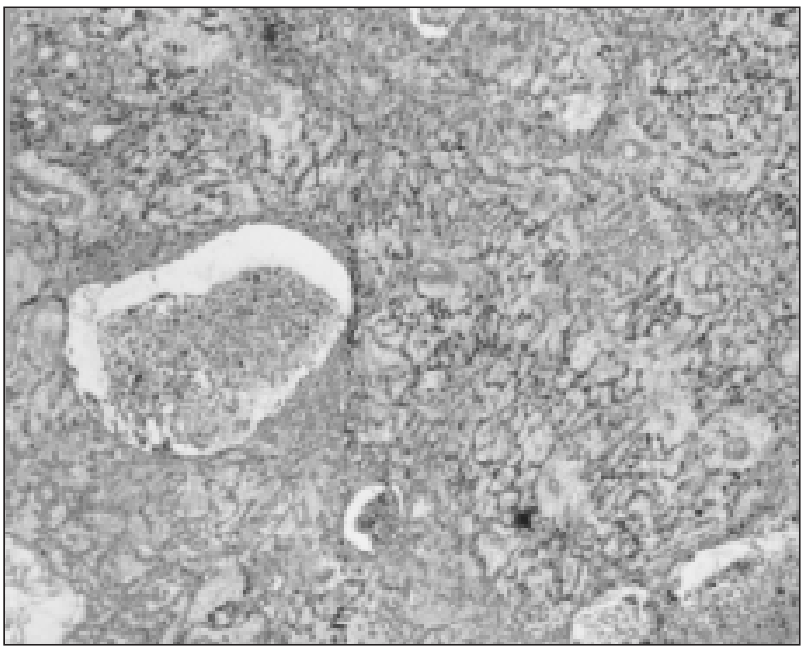

Figura 1 - Neoplasia constituída por cordões anastomosantes e grupos de células neuroepiteliais (H\&E 40x)

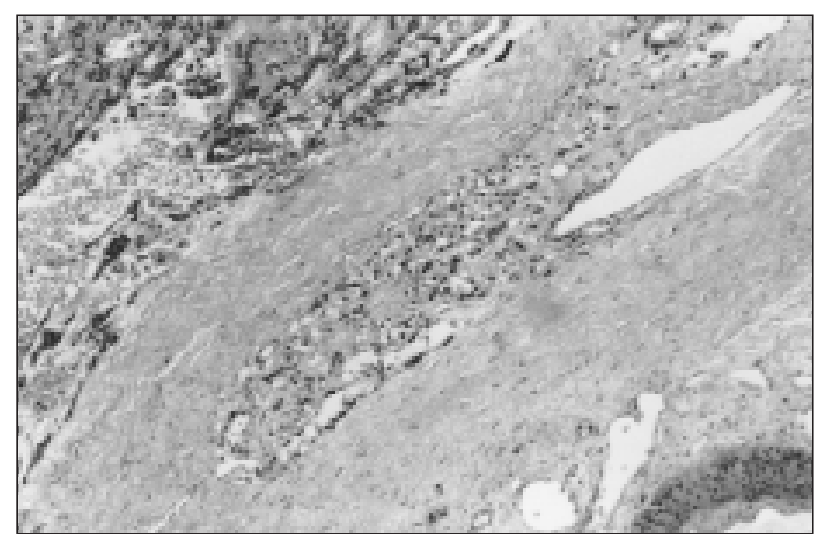

Figura 2 - Infiltração da esclera por estruturas tubulares neoplásicas (H\&E 100x)

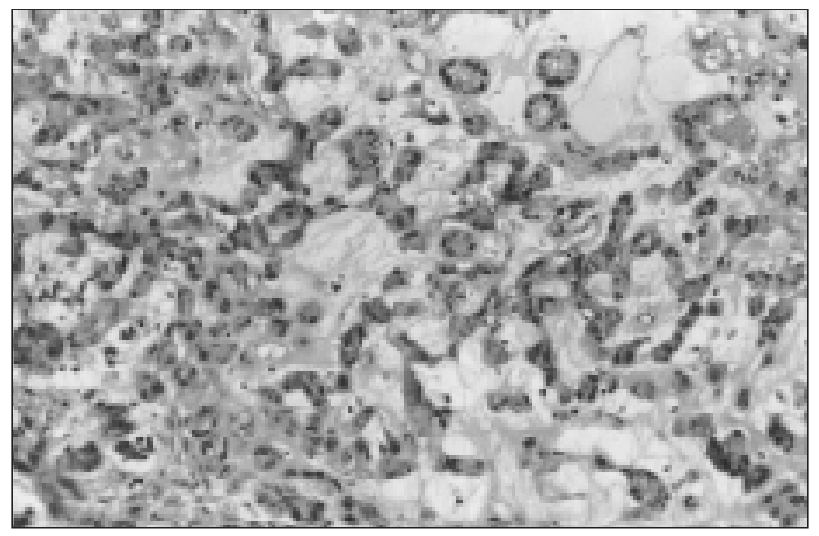

Figura 3 - Cordões constituídos por células cúbicas (H\&E 200x)

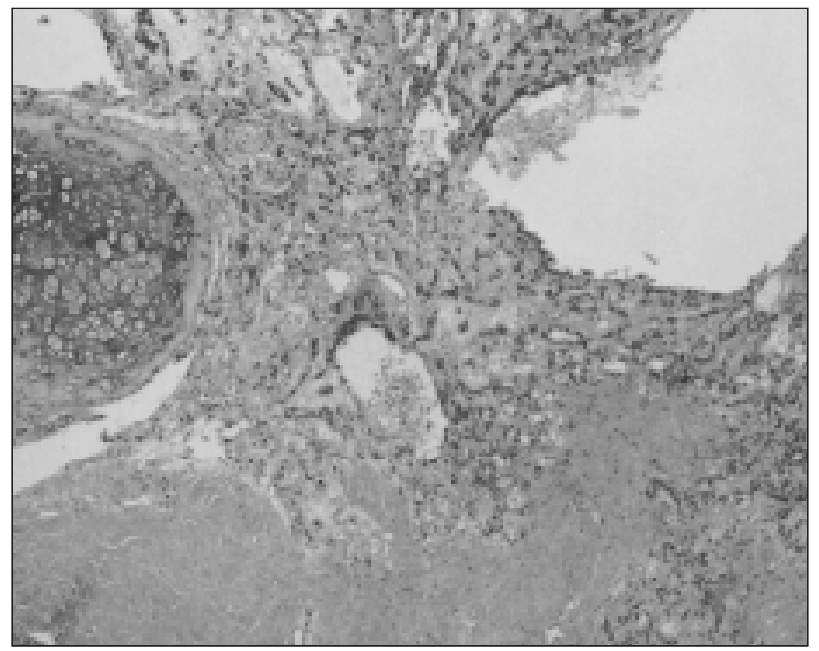

Figura 4 - Ilha de cartilagem hialina (H\&E 40x)

\section{Discussão}

Os meduloepiteliomas ocorrem no corpo ciliar, sendo raramente encontrados no nervo óptico ou na retina (1013). Tornam-se aparentes durante a primeira década de vida, com uma média de idade variando de 4 a 7 anos (1, 6-8, 14, 15). Shields, em uma série de dez casos publicadas em 1996 (6), observou que as manifestações clínicas mais freqüentes foram perda visual devida a subluxação do cristalino, catarata e glaucoma, sendo que $60 \%$ dos pacientes apresentaram hipertensão intra-ocular. Importantes aspectos clínicos foram a dificuldade e o atraso no diagnóstico e no correto tratamento dos pacientes, sendo, em seis dos dez casos, de três a 18 meses a média de tempo para o correto diagnóstico. No presente caso, a paciente permaneceu 20 meses sem o diagnóstico correto da neoplasia.

O tumor é composto por proliferação de células neuroepiteliais, arranjadas em cordões, lençóis e túbulos, entremeadas por espaços císticos, contendo substância basofílica, amorfa, positiva na coloração de alcian blue, compa- 
tível com ácido hialurônico. Os cordões são formados por uma ou muitas camadas de células colunares e cubóides, com núcleos periféricos e citoplasma eosinofílico e granular. Outras áreas são formadas por células neuroblásticas, com matriz fibrilar, núcleos redondos, hipercromáticos e com citoplasma escasso, onde podem ser encontradas rosetas de Flexner-Wintersteiner. Mitoses e atipias celulares são infreqüentes. O tumor é invasivo, comprometendo esclera e trato uveal. Nos casos teratóides, que se estima corresponderem a um terço do total (4), observam-se cartilagem hialina, como no presente relato, tecido muscular esquelético e tecido encefálico. O perfil imunoistoquímico tem demonstrado positividade para enolase neuroespecífica nos túbulos neuroepiteliais e nas rosetas, anticorpos específicos musculares nos feixes de músculo estriado, proteína ácida glial fibrilar e proteína $S$ 100 nas ilhas de tecido neuroglial e vimentina nos elementos mesenquimais $(7,8)$.

O meduloepitelioma intra-ocular pode ser congênito ou adquirido. Os congênitos são derivados do epitélio ciliar indiferenciado, sendo encontrados na infância; os adquiridos são derivados do epitélio diferenciado e acometem adultos (1). Zimmerman, em 1971 (9), classificou estes tumores em teratóides e não-teratóides e em benignos e malignos. Os tumores teratóides são os que contêm elementos heteroplásticos, como cartilagem, músculo esquelético e te- cido encefálico. Os não-teratóides são constituídos por uma proliferação pura de células do epitélio ciliar (diktiomas). Os critérios de malignidade são: 1) áreas pouco diferenciadas de células neuroblásticas, lembrando retinoblastoma; 2) pleomorfismo celular e atividade mitótica; 3 ) áreas sarcomatóides; 4) invasão do estroma uveal e da esclera. Trata-se o presente caso de um meduloepitelioma teratóide maligno, com invasão neoplásica da esclera.

O tratamento atual é a enucleação, devido ao fato de o tumor ser agressivo, diminuindo as chances de recidiva local que ocorrem nos casos de tratamento mais conservador. Nos poucos relatos disponíveis, os pacientes apresentaram uma boa sobrevida após a cirurgia, com baixos índices de recorrências e raras metástases $(1,6-8,14)$. Os pacientes na faixa etária adulta apresentaram formas mais agressivas, com áreas sarcomatosas, alta taxa mitótica, pleomorfismo e pior sobrevida $(6,15)$. Até o presente momento, a paciente relatada neste trabalho apresentase livre de recorrências.

\section{Agradecimentos}

Os autores agradecem ao sr. Nei Boullaf as preparações histológicas e ao dr. José Fillus Neto os comentários construtivos.

\section{Referências}

I. Canning, C.R. et al. Medulloepithelioma (diktyoma). British Journal of Ophthalmology, 72: 764-7, 1988.

2. Badel, J. et al. Carcinome primitif de proces et du corps ciliare. Arch. Ophthalmol., 63: 132-4, 1979.

3. Verhoeff, F.H. et al. A rare arising from the pars ciliaris retinae (teratoneuroma) of a nature hitherto unrecognised, and its relation to the so-called glioma retinae. Trans. Am. Ophthalmol. Soc., 10:351-77, 1904.

4. Fuchs, E. et al. Arch. Clin. Exp. Ophthalmol., 68: 534-87, 1908.

5. Grinker, R.R. et al. Gliomas of the retina, including the results of studies with silver impregnation. Arch. Ophthalmol, 5: 920-35, 1931.

6. Shields, J.A. et al. Congenital neoplasms of the nonpigmented ciliary epithelium (medulloepithelioma). Ophthalmol., 12: 1998-2006, 1996.

7. Steinkuller, P.G. et al. Congenital malignant teratoid neoplasm of the eye and orbit. Ophthalmol., I: 38-42, 1997.

8. Kivela, T. et al. Recurrent medulloepithelioma of the ciliary body. Ophthalmol, 95: 1565-75, 1988.

9. Zimmerman, L.E. et al. Terato-neuroma: a clinical reappraisal in light of the new observations and current concepts of embryonic tumors. Trans. Am. Ophthalmol., 69:210-36, 1971.

10. Reese,A.B. Medulloepithelioma (diktyoma) of the optic nerve. Am. J. Ophthalmol., 44:4-6, 1957.
I I.Anderson, S.R. Medulloepithelioma of the retina. Int. Ophthalmol. Clin., 2: 483-502, 1962.

12. Green, W.R. et al. Malignant terotoid medulloepithelioma of the optic nerve. Arch. Ophthalmol., 91: 45 I-4, 1974.

1 3. Mullaney, J. Primary malignant medulloepithelioma of the retinal stalk. Am. J. Ophthalmol., 77: 499-504, 1974.

14. Vadmal, M. et al. Nonteratoid medulloepithelioma of the retina with electron microscopic and immunohistochemical characterization. Ped. Path. and Lab. Med., 1 6: 663-72, 1996.

15. Husain, S. et al. Malignant nonteratoid medulloepithelioma of the ciliary body in an adult. Ophthalmol., 105: 596-9, 1998.
Endereço para correspondência

Leonora Z. Blind Pope

Serviço de Anatomia Patológica

Universidade Federal do Paraná

Rua General Carneiro 181

CEP 80069-900 - Curitiba-PR

Telefax: (41) 264-1304

e-mail: Izbpope@terra.com.br 